\title{
The role of light in the plants world
}

\author{
Marian Gilewski* \\ Faculty of Electrical Engineering, Bialystok University of Technology, Wiejska 45A, 15-351 Bialystok
}

Received December 14, 2019; accepted December 23, 2019; published December 31, 2019

\begin{abstract}
This letter describes the differences in how people and plants perceive light. This is important in some artificial light applications. In particular, it concerns the horticulture area in which LED lighting is increasingly used. There is a misunderstanding about the specifics of the environment in this area. As a result, even experienced lighting professionals design greenhouse lamps in the same way as for people. This article describes the negative consequences of this approach.
\end{abstract}

The Sun was and will be an essential factor for life on Earth. Sunlight has participated for millions of years in the process of evolution of species: plants, animals and also humans. It provided: life energy, environmental information as well that about synchronized periodic growth phases. When we talk about the role of sunlight in life, we often mean visible radiation in the wavelength range from $380 \mathrm{~nm}$ to $780 \mathrm{~nm}$. This is a wrong and narrow perception of the light role (Fig. 1), which is limited to people.

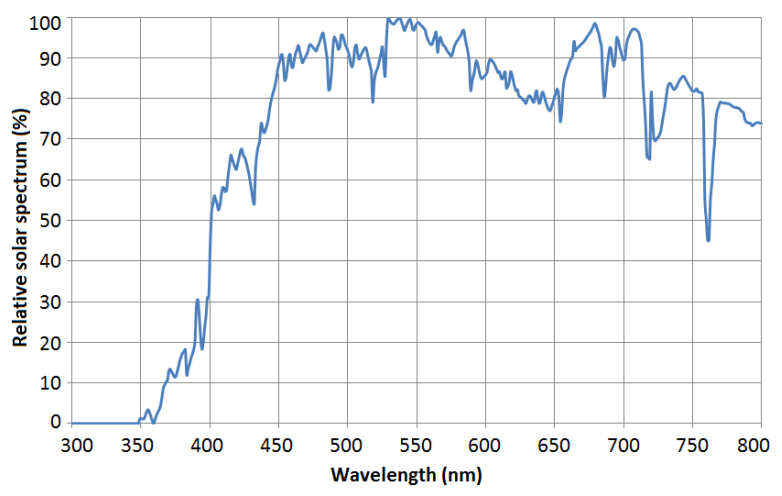

Fig. 1. Typical solar spectrum in the visible range.

Sometimes we accept a range of UV radiation, below 380 $\mathrm{nm}$, because we experience the actinic ultraviolet effects [1]. However, in reality, the solar spectrum is much wider and covers a wavelength up to $4000 \mathrm{~nm}$. With such a wide spectrum, all living organisms use their own narrow bands specific to their species. These radiation bands are different in wavelength and spectrum shape for specific species. This means that people, animals, plants and insects need different kinds of radiation in terms of wavelength and energy. Wavelength,

\footnotetext{
*E-mail: m.gilewski@pb.edu.pl
}

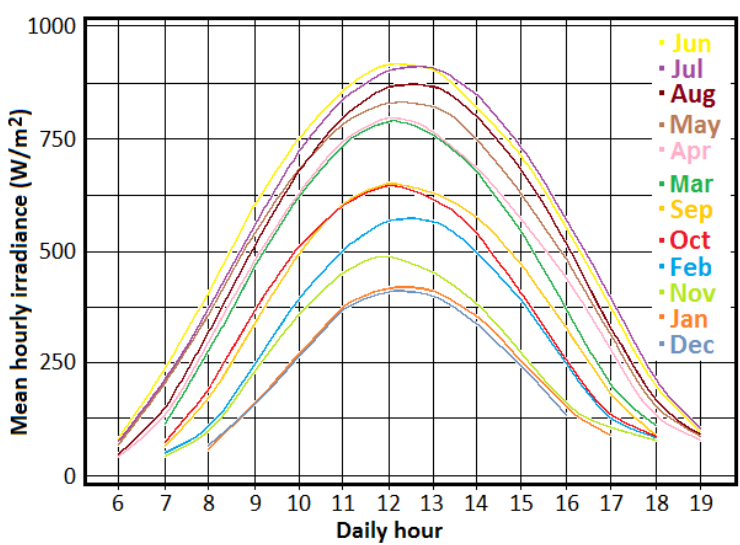

Fig. 2. Examples of monthly and hourly global solar irradiance.

radiation energy and power (flux) perform an important control function in life processes. Sustainable development of the species can only take place within the permissible flux range. In the case of too low a flux, life processes occur slowly, on the other hand, strong light stops plant growth.

The luminous flux reaching the Earth's surface is changeable, it is a slow-changing function of time and latitude (Fig. 2) [2]. The daily photoperiod reaches its maximum flux at local noon, between $1100 \mathrm{hrs}$ and 1300 hrs. In addition, the average long-term photoperiod (monthly averaged) changes by up to $80 \%$ per year. The distribution of daily solar energy combined with the ambient temperature creates a biological clock that synchronizes life processes on Earth. It is a kind of

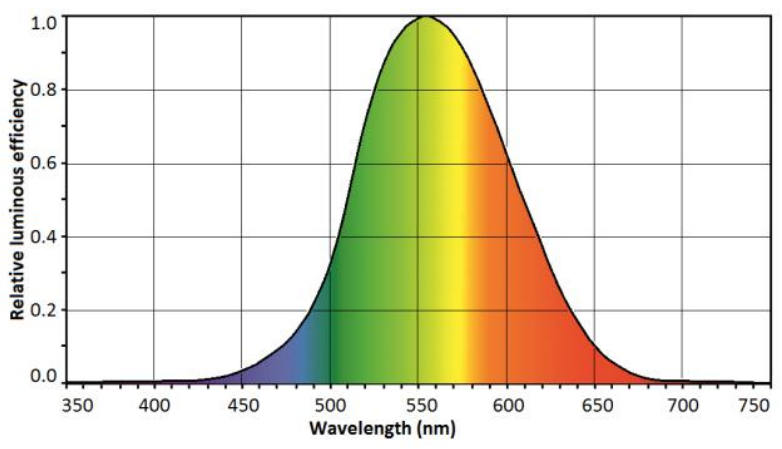

Fig. 3. CIE 1931 luminous efficiency function $V_{\lambda}$ [4].

(C) 2019 Photonics Society of Poland 
communication system that controls daily cycles and longterm life phases. Over the years, we have developed efficient artificial radiation sources. We have given up the natural cycle and, what is worse, we are trying to transfer our lighting habits to the world of animals and plants.

Nevertheless, when we say "seeing the light" we usually mean the anatomy of the eye [3]. The luminous efficiency function (Fig. 3) of the entire eye is the result of the band's sensitivity ( $\mathrm{V}_{\lambda}$-curve). This function has become abasis for defining photometric parameters, developing and designing instruments [5-7]. The photometric approach is a source of confusion in research and practice, because the rest of the lively nature receives radiation in an energetic way. Another source of misunderstanding is the practical use of eye inertia. The flickering light above the fusion frequency is used to control the average flux value [8-10] by engineers to receive proportional optical effects. This kind of light is unnatural.

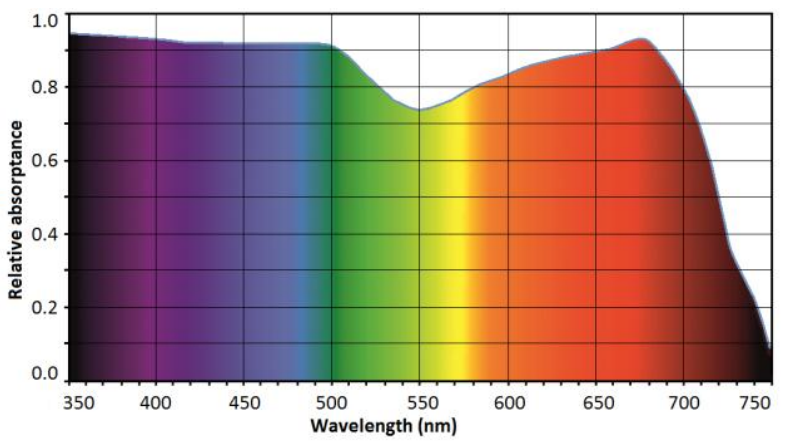

Fig. 4. Average plant spectral absorptance.

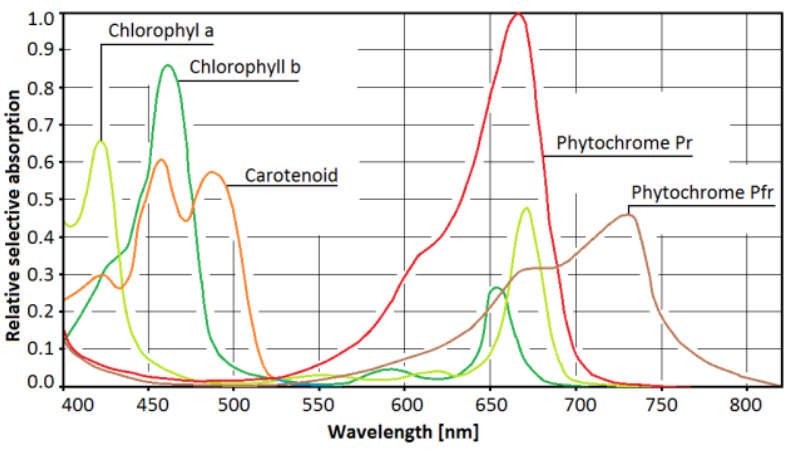

Fig. 5. Absorption spectra of plant species.

Optical radiation in the plants' life performs three main functions: source of energy in photosynthesis, growth synchronizing clock and control of biochemical reactions [11]. In nature, only 4-6\% of solar radiation is used for biomass production [12]. For field and greenhouse crops, industry-specific radiation parameters are used, such as: photosynthetic photon flux (PPF), photosynthetic photon flux density (PPFD) and photosynthetic photon efficiency (PPE) [13]. The spectral absorption of plants is not only a species feature but also depends on the vegetation phase and environmental conditions. In the 70s [14], the first spectral absorption curves of plants were developed. As we can see in (Fig. 4), only a $9 \%$ decrease in absorption was recorded around $550 \mathrm{~nm}$. This contradicts the popular opinion that plants do not absorb and reflect the whole light in the green spectrum. Since this curve expresses the average values of total absorption, it is less useful in practice.

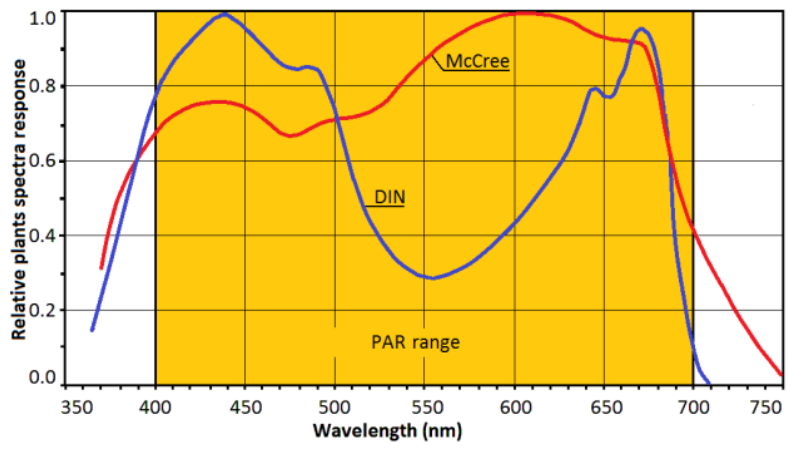

Fig. 6. Relative plants spectra: McCree and DIN standard [16].

In the quantum approach, it is assumed that each absorbed photon excites only one electron (Stark-Einstein law) regardless of its energy. The performance characteristic expressed by the number of photons is known as the McCree curve or quantum efficiency curve. This curve more closely approximates the photosynthesis process for multi-band sources such as LED lamps. As a result of more thorough studies of photosynthetic processes, specific absorption properties were found for plant pigments such as chlorophyll, carotenoids and phytochromes (Fig. 5) [15]. On their basis, another universal photosynthesis efficiency curve was created, approximating the component characteristics peaks (Fig. 6 , blue line) [17]. The photosynthetically active radiation (PAR) waveband has been defined as an optical radiation band from $400 \mathrm{~nm}$ to $700 \mathrm{~nm}$ (Fig. 6) that affects biological processes in plants. Photosynthetic curves in this band are called PAR functions. This is another source of ambiguity, because McCree curves and DIN are sometimes used interchangeably.

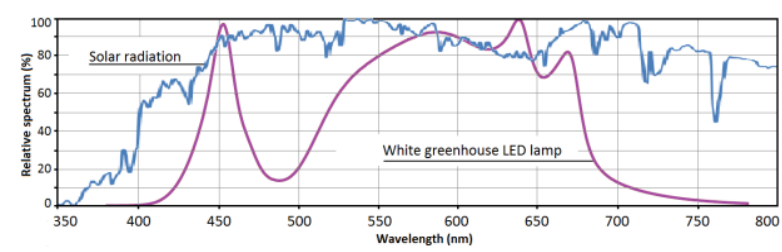

Fig. 7. Distribution flux of the Sun and HLG Elite lamp [22].

In greenhouse lighting, no coherent position has been developed regarding the temporal characteristics of lamps. 
It has been statistically confirmed [18] that artificial extension of the day can stimulate the biomass growth of some crops, but also negatively affects crops health and fruits quality [19-21]. Unfortunately, the community of constructors and manufacturers of greenhouse lamps is dominated by a commercial approach, i.e. energy saving and biomass increase. Currently, three types of LED lamps are dominant in the greenhouse LED lighting. The first of these are white substitutes (Fig. 7): high pressure sodium, ceramic metal halide and fluorescent lamps. The emission spectra of these lamps are not matched to either the solar or PAR spectrum. Another category includes lamps generating radiation in the blue and red band (Fig. 8), so their spectra can approach the DIN curve [23].

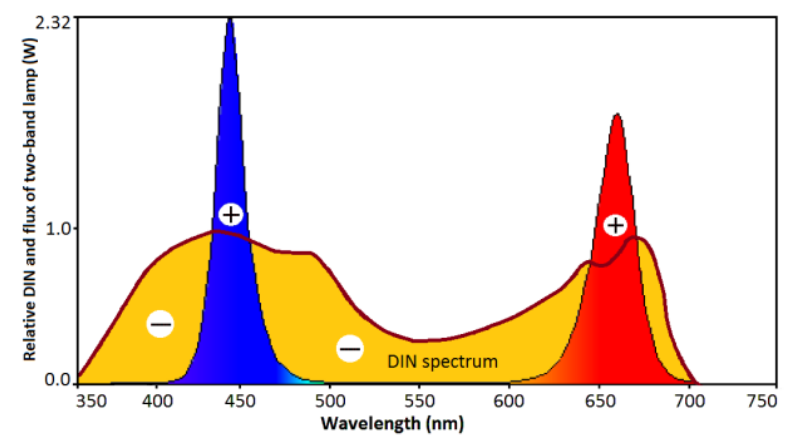

Fig. 8. DIN and dual band LED lamp spectra [15].

However, there is also a spectral mismatch which, despite the power regulation, leaves underexposed (-) or overexposed (+) intervals. Even increasing the number of bands (research lamps category) does not guarantee achieving $95 \%$ convergence with the reference curve, as shown in Fig. 9.

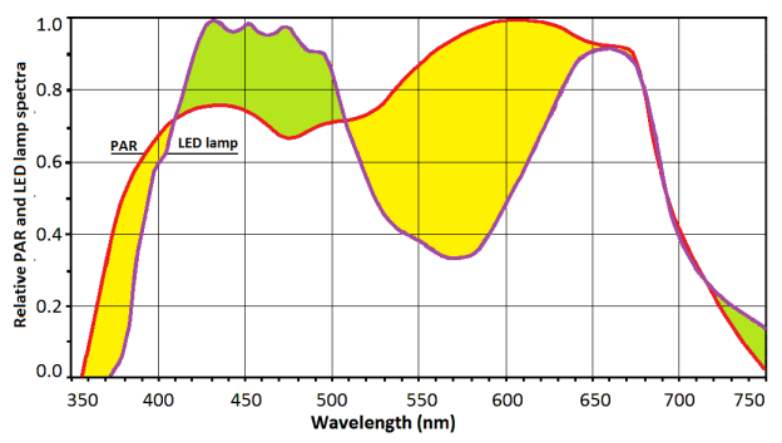

Fig. 9. PAR and 24-band LED lamp spectra [17].

It is obvious that we will not avoid climate instability, nor population growth or metropolis development. Therefore, it will increase the demand for greenhouse plant food. In this situation, the importance of crops artificial lighting will increase. We probably will not build a solar radiation substitute, so we will be forced to accept a lower consumption quality of vegetables and fruits. Similarly, we will not change the pro-economic approach of investors, but we can develop biologically tailored systems in cooperation with plant physiologists. As engineers, we should not see live plants as technical instruments, because their internal processes are more complex and interdependent.

\section{References}

[1] A. R. Young, J. Claveau, A.B. Rossi, J. American Academy of Dermatology 76, 100 (2017)

[2] S. Pashiardis, S.A. Kalogirou, A. Pelengaris, J. Biometrics \& Biostatistics, p. 1-16 (2017).

[3] W. Bommel, Interior Lighting: Visual Mechanism (Springer Nature, Switzerland 2019).

[4] L.T. Sharpe, A. Jagla, W. Jägle, J. Vision 5(11), 948 (2012).

[5] I. Fryc, E. Czech, Proc. SPIE 5064, 18 (2003).

[6] I. Fryc, J. Modern Optics 56(33), 1504 (2009).

[7] I. Fryc, P. Tabaka, Opt. Applicata 49(2), 345 (2019).

[8] M. Liu, Y. Yan, Q. Xue, L. Gong, 6th Int. Conference on Applied Human Factors and Ergonomics, Las Vegas 2015.

[9] W. Wojtkowski, Przeglad Elektrotechniczny 86(10), 260 (2010).

[10] W. Wojtkowski, Przeglad Elektrotechniczny 87(4), 71 (2011).

[11] Y. Berkovich et al., LED crop illumination inside space greenhouses (Elsevier 2017)

[12] C.M. Campillo, R. Fortes, M.H. Prieto, Solar Radiation Effect on Crop Production, 2012. https://www.researchgate.net/publication/ 221929763_Solar_Radiation_Effect_on_Crop_Production.

[13] I. Ashdown, Photometry and Photosynthesis: From Photometry to PPFD, 2015. https://www.researchgate.net/publication/ 284157299_Photometry_and_Photosynthesis_From_Photometry_to_P PFD_Revised.

[14] K.J. McCree, Agricultural Meteorology 9, 191 (1970).

[15] OSRAM Opto Semiconductors, Horticulture Lighting with LEDs, Nov. 2016, www.osram-os.com.

[16] Standard DIN 5031-10 Optical radiation physics and illuminating engineering, https://www.techstreet.com/standards/din-503110?product_id $=2007586$.

[17] EconoLux Indastries Ltd., What Light do Plants Need, Hong Kong, 2016, available: http://econoluxindustries.com/light-plants-need.html.

[18] M.B. Ali, L. Khandaker, S. Oba, J. Food Agric. Environ. 7, 392 (2009).

[19] A. Szmidt-Jaworska, K. Jaworski, A. Tretyn, J. Kopcewicz, J. Plant Physiology 161, 277 (2004).

[20] A. Szmidt-Jaworska, K. Jaworski, J. Kopcewicz, J. Plant Growth Regulation 25, 233 (2006).

[21] A. Szmidt-Jaworska, K. Jaworski, A. Zienkiewicz, M. Lenartowska, J. Kopcewicz, J. Plant Growth Regulation 57, 173 (2009).

[22] Light Laboratory Inc., Goniophotometer Test Report HLG ELITE lamps, https:/horticulturelightinggroup.com/collections/lamps/ products/elite-360-eco.

[23] U.J. Błaszczak, D.A. Aziz, L. Gryko, Proc. SPIE 10445, 1 (2017). 